\title{
Resistência do algodoeiro à ferrugem tropical potencializada pelo silício
}

\author{
Antonia Mirian Nogueira de Moura Guerra ( $\left.{ }^{1}\right)$; Fabrício Ávila Rodrigues ( ${ }^{2}$ ); Paulo Geraldo Berger ( $\left.{ }^{3 *}\right)$; \\ Angélica Fátima Barros ( $\left.{ }^{2}\right)$; Yasmim Cristina Rodrigues $\left({ }^{2}\right)$; Tricia Costa Lima $\left({ }^{4}\right)$ \\ (') Universidade Federal do Oeste do Pará (UFOPA), Instituto de Biodiversidade e Florestas, 68035-110 Santarém (PA), Brasil. \\ (2) Universidade Federal de Viçosa (UFV), Departamento de Fitopatologia, 36570-000 Viçosa (MG), Brasil. \\ (3) UFV, Departamento de Fitotecnia, 36570-000 Viçosa (MG), Brasil. \\ ${ }^{(4)}$ Universidade Estadual de Goiás (UEG), Unidade Universitária de Palmeiras de Goiás, 76190-000 Palmeiras de Goiás (GO), Brasil. \\ (*) Autor correspondente: pgberger@ufv.br
}

Recebido: 28/mar./2013; Aceito: 27/jun./2013

\begin{abstract}
Resumo
Este trabalho teve como objetivo estudar o efeito do silício (Si) sobre componentes de resistência do algodoeiro à ferrugem tropical causada por Phakopsora gossypii. Plantas das cultivares BRS Buriti e FM 993 cresceram em solução nutritiva contendo zero (-Si) ou 2 mmol Si L-1 (+Si). A maior concentração foliar de Si aumentou o período de incubação e o período latente em 9\% e 14,3\%, respectivamente, reduziu a área pustular, a área abaixo da curva de progresso da ferrugem e a área abaixo da curva de progresso da área da pústula em 27,5\%, 36\% e 22\%, respectivamente. Nas plantas das cultivares BRS Buriti e FM 993 supridas com Si houve redução no número de pústulas em 70\% e 30\% e no número de urédias em 40,3\% e 19,5\%, respectivamente. A concentração de compostos fenólicos nas plantas da cultivar BRS Buriti supridas com Si aumentou até os 10 dai e, para a cultivar FM993, até os 30 dai. A concentração de derivados da lignina-ácido tioglicólico aumentou depois dos 20 dai para as duas cultivares supridas com Si. Atividade da peroxidas e aumentou até os 25 dai e os 10 dai para as plantas das cultivares BRS Buriti e FM 993 supridas com Si, respectivamente. A atividade da quitinase aumentou até 10 dai para as plantas da cultivar BRS Buriti e aos 10 e 20 dai para as plantas da cultivar supridas com Si. A atividade da glucanase aumentou até os 10 dai para as plantas da cultivar BRS Buriti supridas com Si e até os 20 dai para as plantas da cultivar FM 993 supridas com Si. Em conclusão, o suprimento de Si contribuiu para aumentar a resistência do algodoeiro à ferrugem devido à maior atividade das enzimas de defesa.
\end{abstract}

Palavras-chave: compostos de defesa, Phakopsora gossypii, resistência.

\section{Cotton resistance to tropical rust mediated by silicon}

\section{Abstract}

The objective of this study was to examine the effect of silicon (Si) on some components of cotton resistance to tropical rust caused by Phakopsora gossypii. Cotton plants from cultivars BRS Buriti and FM 993 were grown in nutrient solution containing 0 $(-\mathrm{Si})$ or $2 \mathrm{mmol} \mathrm{Si} \mathrm{L}^{-1}(+\mathrm{Si})$. The increase in $\mathrm{Si}$ concentration on leaf tissue increased the incubation period and the latent period in $9 \%$ and $14.3 \%$, respectively and reduced the pustule area, the area under cotton leaf rust progress curve, the area under pustule progress curve by $27.5 \%, 36 \%$ and $22 \%$, respectively. In +Si plants, the NP decreased by $70 \%$ and $30 \%$ and the NU by 40.3\% and 19.5\% for cultivars BRS Buriti and FM993, respectively. The concentration of phenolic compounds for + Si plants of cultivar BRS Buriti and FM 993 was high at 10 and 30 dai, respectively. The concentration of derivatives of lignin-thioglycolic acid increased after 20 dai for both cultivars supplied with Si. Peroxidase activity was high at 25 and 10 dai for +Si plants of cultivars BRS Buriti and FM993, respectively. Chitinase activity was high at 10 dai for +Si plants of cultivar BRS Buriti and at 10 and 20 dai for cultivar FM993.Glucanase activity was high at 10 and 20 dai for +Si plants of cultivars BRS Buriti and FM993, respectively. In conclusion, the supply of Si to cotton plants contributed to increase their resistance to rust due to the participation of the defense enzymes.

Key words: compounds of host defense, Phakopsora gossypii, resistance. 


\section{INTRODUÇÃO}

A cultura do algodão (Gossypium hirsutum L.) é uma das mais tradicionais e de maior expressão econômica do Brasil e tem dado sinais de crescimento em termos de área cultivada nos últimos anos (Freire, 2011). Entretanto, uma das principais dificuldades no estabelecimento da cotonicultura em diversas regióes do Brasil e do mundo é a ocorrência de doenças. A ferrugem tropical, causada por Phakopsora gossypii (Arth.) Hirat., foi constatada em lavouras de algodão na região Centro-oeste do Brasil (SuAssuna e Araújo, 2003). O fungo não apresenta distribuição mundial homogênea, concentrando-se principalmente nas regióes dos trópicos (STERNE, 1981), mas de ocorrência esporádica (PNithalingam, 1968). O sintoma característico da ferrugem tropical são pústulas de aspecto ferruginoso (STERNE, 1981). Os sintomas aparecem primeiramente nas folhas, principalmente nas mais velhas para as mais novas, podendo causar desfolha prematura (SuAssuna e Araújo, 2003). A ferrugem caracteriza-se por pequenos pontos de coloração vermelho-arroxeada, localizados na epiderme abaxial; as pústulas rompem a epiderme e com o decorrer do tempo liberam uma massa pulverulenta de uredosporos (Benedo, 1995; Suassuna e Araújo, 2003; Sterne, 1981).

A principal estratégia de manejo da ferrugem é o controle químico, sendo apresentado como alternativa para garantir o desenvolvimento sustentável da cultura no Cerrado, visto que a maioria das cultivares de algodão utilizadas não possuem resistência genética (Suassuna e Araújo, 2003). É sabido que o fornecimento de silício $(\mathrm{Si})$ às plantas tem contribuído de forma eficiente para o controle de doenças fúngicas em dicotiledôneas como banana, tomate, café, abóbora, pepino, videira e roseira (BÉLANGER et al., 2003; BowEN et al., 1992; French-Monar et al., 2010; Huang et al., 2011; Menzies et al., 1991; Pereira et al., 2009; Vermeire et al., 2011). Dessa forma, essa medida alternativa de controle vem ganhando cada vez mais aceitação e é promissora para os produtores considerando os enormes prejuízos que as diferentes doenças têm causado na produção das mais diversas culturas.

$\mathrm{O} \mathrm{Si}$, apesar de não ser considerado essencial para o crescimento das plantas, pode ser absorvido pelo arroz a níveis que excedem os macronutrientes (EpsTein, 1999). Essencial ou não, o papel do Si nas plantas tem sido cada vez mais de interesse dos pesquisadores devido aos seus inúmeros benefícios, principalmente sob condiçóes de estresse. Do ponto de vista morfológico, a deposição e polimerização do ácido monossilícico abaixo da cutícula formam uma camada dupla de cutícula-sílica (YoshidA, 1965) que pode impedir ou atrasar a penetração de patógenos (KIM et al., 2002). Outro mecanismo proposto é que o Si solúvel tenha um papel ativo, potencializando mecanismos de defesa das plantas com o aumento na produção de compostos fenólicos, aumento nos níveis de algumas classes de fitoalexinas e também potencializando a ativação de alguns genes que codificam proteínas PR (ChÉrIf et al., 1994; RodRIGUes et al., 2003; 2004; 2005). No entanto, a exata natureza da interação entre o Si solúvel com as vias bioquímicas de defesa da planta permanece desconhecida.

Não existe nenhuma pesquisa publicada acerca dos efeitos do Si sobre o controle das doenças do algodoeiro, particularmente da ferrugem tropical, e sobre seus efeitos sobre os componentes de resistência do hospedeiro e os possíveis mecanismos bioquímicos envolvidos na resistência. Assim, este trabalho objetivou determinar o efeito do Si sobre alguns componentes de resistência, bem como sobre os mecanismos bioquímicos que podem estar envolvidos com o aumento da resistência do algodoeiro à ferrugem tropical.

\section{MATERIAL E MÉTODOS}

\section{Preparo da solução nutritiva e crescimento das plantas de algodão}

Sementes de algodão das cultivares BRS Buriti e FM 993 foram lavadas em solução de hipoclorito de sódio (10\%) por dois minutos, seguidas de lavagem em água destilada por três minutos e germinadas em leito de areia lavada e autoclavada. Dez dias após a germinação, três plântulas foram transferidas para vasos plásticos de cinco litros contendo solução nutritiva de Hoagland e Arnon (1950) modificada, constituída de: $6,0 \mathrm{mmol} \mathrm{L} \mathrm{KNO}_{3} ; 1,0 \mathrm{mmol} \mathrm{L} \mathrm{NH}_{4} \mathrm{H}_{2} \mathrm{PO}_{4} ; 2,0 \mathrm{mmol} \mathrm{L}^{-1}$ $\mathrm{MgSO}_{4} .7 \mathrm{H}_{2} \mathrm{O} ; 4,0 \mathrm{mmol} \mathrm{L}-1 \mathrm{Ca}\left(\mathrm{NO}_{3}\right)_{2} ; 0,3 \mu \mathrm{mol} \mathrm{L}^{-1}$ $\mathrm{CuSO}_{4} \cdot 5 \mathrm{H}_{2} \mathrm{O} ; 1,3 \mu \mathrm{mol} \mathrm{L}^{-1} \mathrm{ZnSO}_{4} \cdot 7 \mathrm{H}_{2} \mathrm{O} ; 46 \mu \mathrm{mol} \mathrm{L}^{-1}$ $\mathrm{H}_{3} \mathrm{BO}_{3} ; 12,6 \mu \mathrm{mol} \mathrm{L}^{-1} \mathrm{MnCl}_{2} .4 \mathrm{H}_{2} \mathrm{O} ; 0,1 \mu \mathrm{mol} \mathrm{L}^{-1}\left(\mathrm{NH}_{4}\right)$ $6 \mathrm{Mo}_{7} \mathrm{O}_{24} \cdot 4 \mathrm{H}_{2} \mathrm{O} ; 45 \mu \mathrm{mol} \mathrm{L}^{-1} \mathrm{FeSO}_{4} \cdot 7 \mathrm{H}_{2} \mathrm{O}$-EDTA bissódico. $\mathrm{O}$ ácido monossilícico obtido pela passagem do silicato de potássio através de uma coluna contendo resina trocadora de cátions (Amberlite IRA 410) (Ma e TAKahashi, 2002) foi adicionado à solução nutritiva nas concentraçôes de zero $(-\mathrm{Si})$ e $2 \mathrm{mmol} \mathrm{Si} \mathrm{L} \mathrm{L}^{-1}(+\mathrm{Si})$. Foi utilizada solução nutritiva a meia força iônica incluindo a adição ou não do ácido monossilícico. Após sete dias, a concentração da solução utilizada foi modificada para força total. A soluçáo nutritiva foi aerada, trocada a cada quatro dias e o $\mathrm{pH}$ foi verificado diariamente e mantido entre 5,5 e 6,0 .

\section{Obtenção do inóculo de P. gossypii e inoculação das plantas}

O inóculo de $P$. gossypii foi obtido de plantas de algodão doentes coletadas em Viçosa (MG), 2045'14”S; 4252'55”W, $649 \mathrm{~m}$. As folhas contendo pústulas de $P$. gossypii foram lavadas com água destilada com auxílio de um pincel para uma melhor retirada dos uredosporos e, posteriormente, 
a suspensão obtida foi filtrada em gazes para a retirada de impurezas. A suspensão resultante foi homogeneizada e ajustada para a concentração de $2,5 \times 10^{5}$ uredosporos de P. gossypii $\mathrm{mL}^{-1}$. Tween $20\left(0,1 \mathrm{~mL} 100 \mathrm{~mL}^{-1}\right.$ de suspensão) e gelatina foram adicionados à suspensão $(1 \% \mathrm{p} / \mathrm{v})$ para aumentar a aderência dos uredosporos à superfície foliar. Plantas de algodoeiro no estádio V4 (30 dias após transplantio) (Marur e RuANo, 2001) foram inoculadas com a suspensão de uredosporos. As plantas de cada vaso receberam $30 \mathrm{~mL}$ da suspensão de uredosporos. Após a inoculação, as plantas foram transferidas para câmara de nevoeiro a $25 \pm 2^{\circ} \mathrm{C}$ e umidade relativa de $90 \pm 5 \%$ com fluxo contínuo de luz por $24 \mathrm{~h}$ e, em seguida, transferidas para câmara de crescimento com temperatura ambiente e umidade relativa de $50 \pm 5 \%$, onde permaneceram até o final das avaliaçōes.

\section{Quantificação dos componentes de resistência}

Os seguintes componentes de resistência foram avaliados: período de incubaçáo $(\mathrm{PI})$, período latente $\left(\mathrm{PL}_{60}\right)$, incidência (I), número de pústulas (NP), número de urédias (NU), severidade final, área pustular (AP), foi calculada a área abaixo da curva do progresso da ferrugem (AACPF) e a área abaixo da curva de progresso da área da pústula (AACPAP), conforme modelo proposto por SHANER e Finney (1977). Em cada planta foram marcadas três folhas usadas para avaliar os componentes de resistência. $\mathrm{O}$ aparecimento dos sintomas da ferrugem em cada folha marcada foi avaliado a cada $24 \mathrm{~h}$ a partir do $5^{\circ}$ dia após inoculação (dai). A incidência de plantas com sintomas da ferrugem, em porcentagem, foi avaliada no décimo dai. Dez urédias em cada folha marcada foram selecionadas aleatoriamente e examinadas a cada $24 \mathrm{~h}$ com uma lupa de bolso (30×) para determinar o início da esporulação. $\mathrm{O} \mathrm{PL}_{60}$ ocorreu quando $60 \%$ das urédias marcadas e examinadas apresentavam liberaçáo de uredosporos. A severidade e a área pustular foram avaliadas a partir do $15^{\circ}$ dai e depois a cada cinco dias até o $35^{\circ}$ dai. Para a severidade, foram dadas notas com relaçáo a percentagem da área foliar afetada pela ferrugem. A área pustular foi avaliada medindo-se cinco pústulas selecionadas em cada folha com paquímetro digital. A área abaixo da curva do progresso da ferrugem (AACPF) e a área abaixo da curva do progresso da área pustular (AACPAP) foram calculadas usando-se a integraçáo trapezoidal das curvas de progresso da severidade da ferrugem e da área pustular, respectivamente, seguindo a fórmula proposta por SHANER e Finney (1977). No 35० dai, as folhas marcadas foram coletadas e, com uma lupa, numa área de $1 \mathrm{~cm}^{2}$, foram contados o número de urédias e de pústulas. Foram realizadas duas contagens, uma de cada lado da folha.

\section{Determinação da concentração de compostos fenólicos solúveis totais (CFST)}

Amostras de folhas foram coletadas em nitrogênio líquido e imediatamente armazenadas em ultrafreezer a $-80^{\circ} \mathrm{C}$ até a análise. Amostras de $0,1 \mathrm{~g}$ foram maceradas em nitrogênio líquido. $\mathrm{O}$ macerado foi homogeneizado com $1,5 \mathrm{~mL}$ de metanol $80 \%$ e extraído durante $12 \mathrm{~h}$ em mesa agitadora orbital $(150 \mathrm{rpm})$, a temperatura ambiente $\left(-25^{\circ} \mathrm{C}\right)$. Os tubos foram cobertos com papel alumínio para proteger o extrato metanólico da oxidação pela luz. O extrato metanólico verde escuro foi centrifugado a $12.000 \mathrm{~g}$ por $5 \mathrm{~min}$ e, após centrifugação, o sobrenadante foi transferido pra um novo tubo e o resíduo mantido a $-80^{\circ} \mathrm{C}$, para determinação da concentração dos derivados da lignina-ácido tioglicólico. A metodologia proposta por ZIESLIN e BEN-ZAKEN (1993), com algumas modificaçôes, foi usada para determinação da concentração de CFST. Adicionaram-se $150 \mu \mathrm{L}$ do reagente Folin \& Ciocalteau's Phenol 0,25 M (Sigma-Aldrich, São Paulo, SP, Brasil) a $150 \mu \mathrm{L}$ do extrato metanólico. A mistura foi homogeneizada e mantida a temperatura ambiente $\left(\sim 25^{\circ} \mathrm{C}\right)$ por $5 \mathrm{~min}$. Posteriormente, $150 \mu \mathrm{L}$ de carbonato de sódio $1 \mathrm{M}$ foram adicionados à mistura, a qual foi homogeneizada novamente e mantida a temperatura ambiente. Após $10 \mathrm{~min}$, adicionou-se $1 \mathrm{~mL}$ de água destilada à mistura, que permaneceu em temperatura ambiente $\left(\sim 25^{\circ} \mathrm{C}\right)$ por $30 \mathrm{~min}$. A absorbância das amostras foi medida a $725 \mathrm{~nm}$. A concentraçáo de CFST foi expressa em mg de compostos fenólicos (expresso em catecol) por kg de folha fresca.

\section{Determinação da concentração dos derivados da lignina-ácido tioglicólico (DLATG)}

Adicionou-se 1,5 mL de água estéril ao resíduo obtido após a extração dos CFST. Após a homogeneização, a mistura foi centrifugada a $12.000 \mathrm{~g}$ por $5 \mathrm{~min}$. O sobrenadante foi descartado e o resíduo foi seco a $65^{\circ} \mathrm{C}$ por $\sim 12 \mathrm{~h}$. O resíduo alcoólico-insolúvel seco, contendo lignina e ácidos fenólicos associados à parede celular, foi usado para determinação de lignina de acordo com a metodologia de BARBER e Ride (1988). Um volume de $1,5 \mathrm{~mL}$ da solução de ácido tioglicólico (Sigma-Aldrich, São Paulo, SP, Brasil) e HCl 2 N (1:10) foram adicionados ao resíduo seco. Os tubos foram levemente agitados para hidratar o resíduo e, em seguida, foram colocados em banho-maria $\left(100^{\circ} \mathrm{C}\right)$. Após $4 \mathrm{~h}$, os tubos foram colocados no gelo por dez minutos. A mistura foi centrifugada a $12.000 \mathrm{~g}$ por $10 \mathrm{~min}$, o sobrenadante foi descartado e o precipitado foi lavado com $1,5 \mathrm{~mL}$ de água destilada estéril e a seguir centrifugado a $10.000 \mathrm{~g}$ por $10 \mathrm{~min}$. Após a centrifugação, o sobrenadante foi descartado

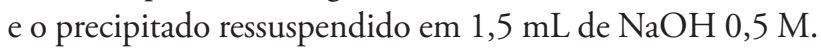
A mistura foi agitada em mesa agitadora orbital (150 rpm), 
a temperatura ambiente $\left(\sim 25^{\circ} \mathrm{C}\right)$ por $12 \mathrm{~h}$. A mistura foi centrifugada a $10.000 \mathrm{~g}$ por 10 min e o sobrenadante foi transferido para um novo tubo. Após a adição de $200 \mu \mathrm{L}$ de HCL concentrado ao sobrenadante, os tubos foram transferidos para uma bandeja com gelo e mantidos na geladeira $\left(4^{\circ} \mathrm{C}\right)$ por $4 \mathrm{~h}$ para precipitação dos DLATG. Após a centrifugação a $10.000 \mathrm{~g}$ por $10 \mathrm{~min}$, o sobrenadante foi descartado e o precipitado, de cor laranja-amarronzada, foi dissolvido em $2 \mathrm{~mL}$ de $\mathrm{NaOH} 0,5 \mathrm{M}$. A leitura da absorbância foi realizada a $290 \mathrm{~nm}$. A concentração dos DLATG foi expressa em $\mathrm{mg} \mathrm{kg}^{-1}$ de folha fresca utilizando-se uma curva padrão obtida com diferentes concentraçôes de lignina alcalina, éter 2-hidroxipropil (Sigma-Aldrich, São Paulo, SP, Brasil).

\section{Determinação da atividade de enzimas de defesa}

Amostras da folha índice das plantas foram coletadas aos $10,15,20,25,30$ e 35 dai. Amostras de folhas coletadas de plantas não inoculadas $(0 \mathrm{~h})$ com $P$. gossypii serviram como controle. As amostras foram mantidas em nitrogênio líquido durante a coleta e armazenadas em ultrafreezer à $-80^{\circ} \mathrm{C}$ até serem analisadas.

Atividade de peroxidases (POX, EC 1.11.1.7): o extrato enzimático foi obtido pela maceração de $0,2 \mathrm{~g}$ de folhas em nitrogênio líquido seguida de homogeneização em $2 \mathrm{~mL}$ do meio de extração composto de $0,1 \mathrm{M}$ tampão fosfato de potássio (pH 6,8), $1 \mathrm{mM}$ fenilmetilsulfonilflúor (PMSF), 0,1 mM ácido etilenodiamino tetra-acético (EDTA) e $200 \mathrm{mg}$ de polivinilpolipirrolidona (PVPP). O homogeneizado foi centrifugado a $12.000 \mathrm{~g}$ por $15 \mathrm{~min}$ a $4^{\circ} \mathrm{C}$ e o sobrenadante foi utilizado no ensaio enzimático. A atividade da POX foi determinada conforme metodologias propostas por CHANCE e Maehley (1955) e Kar e Mishra (1976). No ensaio colorimétrico, utilizou-se pirogalol e peróxido de hidrogênio como substratos. Para a reação foram adicionados $340 \mu \mathrm{L}$ de água destilada, $250 \mu \mathrm{L}$ do tampão fosfato de potássio $100 \mathrm{mM}$ (pH 6,8), $200 \mu \mathrm{L}$ de pirogalol $100 \mathrm{mM}, 200 \mu \mathrm{L}$ de peróxido de hidrogênio $100 \mathrm{mM}$ e $10 \mu \mathrm{L}$ do extrato. As leituras de absorbância foram realizadas a $420 \mathrm{~nm}$ a cada 10 s durante um minuto. A atividade da POX foi medida utilizando-se para os cálculos o coeficiente de extinção molar 2,47 $\mathrm{mM}^{-1} \mathrm{~cm}^{-1}$ (Chance e Maehley, 1955).

Atividade de polifenoloxidases (PPO, EC 1.10.3.1): a obtenção do extrato enzimático foi feita da mesma forma que para a POX. A atividade da PPO foi determinada conforme metodologias propostas por CHANCE e MAEHLEY (1955) e Kar e Mishra (1976). No ensaio colorimétrico, utilizou-se o pirogalol a $100 \mathrm{mM}$ como substrato. A reação foi composta por $520 \mu \mathrm{L}$ de água destilada, $250 \mu \mathrm{L}$ do tampão fosfato de potássio $100 \mathrm{mM}$ (pH 6,8), $200 \mu \mathrm{L}$ de pirogalol $100 \mathrm{mM}$ e $30 \mu \mathrm{L}$ do extrato. As leituras de absorbância foram realizadas a $420 \mathrm{~nm}$ a cada $10 \mathrm{~s}$ durante um minuto.
A atividade da enzima foi medida utilizando-se para os cálculos o coeficiente de extinção molar de $2,47 \mathrm{mM}^{-1} \mathrm{~cm}^{-1}$ (Chance e Maehley,1955).

Atividade de quitinases (QUI, EC 3.2.1.14): o extrato enzimático foi obtido pela maceração de $0,2 \mathrm{~g}$ de folhas em nitrogênio líquido seguida de homogeneização em $2 \mathrm{~mL}$ do meio de extração composto de tampão fosfato de sódio $50 \mathrm{mM}$ ( $\mathrm{pH}$ 6,5), $1 \mathrm{mM}$ PMSF e $200 \mathrm{mg}$ de PVPP. O homogeneizado foi centrifugado a $20.000 \mathrm{~g}$ por 25 min a $4^{\circ} \mathrm{C}$ e o sobrenadante foi utilizado no ensaio enzimático. A determinaçáo da atividade da QUI foi conforme metodologia proposta por Roberts e Selitrennikoff (1988), modificada por Harman et al. (1993), utilizando-se como substrato o p-nitrofenil- $\beta$-D-N-N'-diacetilquitobiose (PNP) (Sigma-Aldrich, São Paulo, SP, Brasil). O meio de reação foi composto por $470 \mu \mathrm{L}$ de tampão acetato de sódio $50 \mathrm{mM}$ (pH 5,0), $10 \mu \mathrm{L}$ de PNP a $2 \mathrm{mgmL}^{-1}$ e $20 \mu \mathrm{L}$ do extrato vegetal, incubado a $37^{\circ} \mathrm{C}$ por $2 \mathrm{~h}$. A reação foi parada acrescentando-se $500 \mu \mathrm{L}$ de acetato de sódio de $50 \mathrm{mM}$ $(\mathrm{pH} 5,0)$. As leituras de absorbância foram realizadas a $410 \mathrm{~nm}$. Foi utilizado para o cálculo o coeficiente de extinçáo molar de $7 \mathrm{M}^{-1} \mathrm{~cm}^{-1}$.

Atividade de $\beta$-1,3-glucanases (GLU, EC 3.2.1.6): o extrato enzimático foi obtido da mesma forma que para a QUI. A atividade da GLU foi determinada conforme metodologia descrita por LeVER (1972) com algumas modificaçóes. O ácido 3,5-dinitrosalicílico (DNS) foi usado em substituição à hidrazida do ácido $p$-hidroxibenzóico. O meio de reação foi constituído de $230 \mu \mathrm{L}$ de tampão acetato de sódio $100 \mathrm{mM}$ $(\mathrm{pH} 5,0), 250 \mu \mathrm{L}$ da soluçáo de substrato da laminarina $\left(4 \mathrm{mg} \mathrm{mL}^{-1}\right)$ e $20 \mu \mathrm{L}$ do extrato vegetal, incubado a $45^{\circ} \mathrm{C}$ por $30 \mathrm{~min}$. Após esse período acrescentaram-se ao meio de reaçáo $500 \mu \mathrm{L}$ de DNS e em seguida essa mistura foi aquecida a $100^{\circ} \mathrm{C}$ por $5 \mathrm{~min}$. Após o resfriamento em gelo até a temperatura de $30^{\circ} \mathrm{C}$, as amostras tiveram absorbância determinada a $540 \mathrm{~nm}$.

A concentração de proteínas utilizada para o cálculo da atividade das enzimas foi obtida pelo método de BRADFORD (1976) usando albumina sérica bovina como padrão.

\section{Determinação da concentração foliar de Si}

Ao $35^{\circ}$ dai, as folhas das plantas avaliadas no experimento sobre componentes de resistência foram coletadas, lavadas em água destilada e secas em estufa com ventilação forçada de ar a $70^{\circ} \mathrm{C}$ até atingir peso constante. Posteriormente, as folhas foram trituradas em moinho tipo Thomas-Wiley (Thomas Scientific, Swedesboro, NJ), equipado com peneira de 20 mesh para determinação da concentração foliar de Si conforme proposto por KoRNDÖRFER et al. (2004).

Coleta de amostras de folhas para microscopia eletrônica de varredura: para as análises microscópicas foram coletados aos 35 dai dez fragmentos $\left(\sim 25 \mathrm{~mm}^{2}\right)$ de folhas. Os fragmentos foram transferidos para vidros contendo fixativo glutaraldeído 
2,5\% em tampão cacodilato de sódio $0,1 \mathrm{M}(\mathrm{pH} 7,2)$ e armazenados em geladeira. Após 15 dias, os fragmentos foram lavados com tampão cacodilato de sódio por quatro vezes durante $10 \mathrm{~min}$ cada e desidratados em uma série alcoólica de 30\%, 50\% e 70\%, com intervalos de $15 \mathrm{~min}$ entre as trocas, sendo realizadas três passagens na última concentração no mesmo intervalo de tempo. As amostras foram pós-fixadas durante duas horas a temperatura ambiente com tetróxido de ósmio a $1 \%$ em tampão cacodilato de sódio $0,1 \mathrm{M}(\mathrm{pH} 7,2)$. Após uma nova desidratação em uma série alcoólica de $80 \%, 95 \%$ e $100 \%$, os fragmentos foram submetidos à secagem no ponto crítico (Balzers, modelo CPD020) e as amostras foram montadas sobre suportes metálicos de alumínio previamente cobertos com fita adesiva dupla face. Em seguida, os fragmentos foram cobertos com ouro por meio de metalização no aparelho SputterCoater acoplado a um FreezingDrying Unit (Balzers, FDU010) e, posteriormente, observados no microscópio eletrônico de varredura (LEO, modelo $1430 \mathrm{VP}$ ) operado a $10 \mathrm{Kv}$ para obtençấo das eletromicrografias.

\section{Delineamento experimental e análise estatística}

O delineamento experimental foi inteiramente casualizado em esquema fatorial $2 \times 2$ com seis repetiçóes, exceto para a coleta de material para análises enzimáticas, realizada com quatro repetiçóes. Os fatores estudados foram duas cultivares de algodão (BRS Buriti e FM 993) e duas doses de Si (0 e $\left.2 \mathrm{mmol} \mathrm{Si} \mathrm{L}^{-1}\right)$. Cada unidade experimental foi composta por um vaso plástico contendo cinco plantas de algodão. Os dados obtidos para cada variável foram submetidos à análise de variância (ANOVA) e as médias dos tratamentos foram comparadas pelo test $-t(\mathrm{p} \leq 0,05)$, a interação doses de silício $\times$ cultivares foi comparada pelo teste Tukey $(\mathrm{p} \leq 0,05)$ utilizando-se o SAS versão 6.12 (SAS Institute, Inc., Cary, NC). A concentração de Si nos tecidos foliares foi correlacionada com os componentes de resistência do hospedeiro.

\section{RESULTADOS}

\section{Componentes de resistência do algodoeiro à ferrugem tropical}

O fator doses de Si foi significativo $(\mathrm{p} \leq 0,05)$ para o PI, $\mathrm{PL}_{60}$, I, SF, AP, AACPF, AACPAP e concentração foliar de Si. Houve aumento de $9 \%$ e $14,3 \%$ para PI e $\mathrm{PL}_{60}$, respectivamente, para o tratamento +Si em relação ao tratamento -Si (Tabela 1). A I, $\mathrm{SF}, \mathrm{AP}, \mathrm{AACPF}$ e AACPAP foram reduzidas significativamente $(\mathrm{p} \leq 0,05)$ em $86,49,27,5,36$ e 22 para o tratamento $+\mathrm{Si}$ em relação ao tratamento -Si (Tabela 1). A concentração foliar de Si aumentou em 85\% para o tratamento $+\mathrm{Si}$ em relação ao tratamento - $\mathrm{Si}$ (Tabela 1 ). O fator cultivares não foi significativo $(\mathrm{p}>0,05)$ para nenhum dos componentes de resistência estudados (Tabela 1).

A interação doses de silício $\times$ cultivares foi significativa $(\mathrm{p} \leq 0,05)$ para NU e NP (Tabela 2). O NP foi reduzido significativamente $(\mathrm{p} \leq 0,05)$ em $70 \%$ e $30 \%$ nas cultivares BRS Buriti e FM 993, respectivamente, para o tratamento +Si em relaçáo ao tratamento - $\mathrm{Si}$ (Tabela 2). Para o NU houve redução de 40,3\% e 19,5\% nas cultivares BRS Buriti e FM 993, respectivamente, para o tratamento + Si em relação ao tratamento -Si (Tabela 2).

\section{Correlação de Pearson}

A correlaçáo concentraçáo foliar de Si com PI e $\mathrm{PL}_{60}$ foi significativa pelo teste $\mathrm{F}$ e positiva $(r=0,42$ e $0,71, \mathrm{p} \leq 0,01$, respectivamente) e significativa e negativa para I, SF, AP, AACPF, AACPAP, NP e NU $(r=-0,41 ;-0,56 ;-0,47$; $-0,46 ;-0,48 ;-0,69$ e $-0,83, p \leq 0,01$, respectivamente).

Tabela 1. Período de incubação $(\mathrm{PI})$, período latente $\left(\mathrm{PL}_{60}\right)$, incidência $(\mathrm{I})$, severidade final $(\mathrm{SF})$, área da pústula $(\mathrm{AP})$, área abaixo da curva de progresso da ferrugem (AACPF), área abaixo da curva de progresso da área da pústula (AACPAP) e concentração foliar de Si em folhas de plantas de algodão das cultivares BRS Buriti e FM 993 crescidas em solução nutritiva contendo (+Si) ou não (-Si) silício (Si) e infectadas por Phakopsora gossypii

\begin{tabular}{|c|c|c|c|c|c|c|c|c|}
\hline \multirow{2}{*}{$\begin{array}{c}\text { Fatores } \\
\text { Silício }\end{array}$} & \multicolumn{8}{|c|}{ Variáveis } \\
\hline & PI (dias) & $\mathrm{PL}_{60}$ (dias) & I (\%) & SF (\%) & AP $\left(\mathrm{mm}^{2}\right)$ & AACPF & AACPAP & Si (\%) \\
\hline$-\mathrm{Si}$ & 11,52 & 19,98 & 13,21 & 14,73 & 7,15 & 95,72 & 60,67 & 0,09 \\
\hline$+\mathrm{Si}$ & 12,54 & 22,83 & 1,83 & 7,53 & 5,18 & 61,19 & 47,29 & 0,59 \\
\hline Teste- $t$ & $0,07^{*}$ & $0,07^{*}$ & $9,52^{*}$ & $4,18^{*}$ & $1,49^{*}$ & $25,80^{*}$ & $8,55^{*}$ & $0,09^{*}$ \\
\hline \multicolumn{9}{|l|}{ Cultivares } \\
\hline BRS Buriti & 11,79 & 21,53 & 8,63 & 12,19 & 6,47 & 87,27 & 56,77 & 0,36 \\
\hline FM 993 & 12,28 & 21,28 & 6,42 & 10,07 & 6,13 & 69,65 & 51,18 & 0,31 \\
\hline Teste- $t$ & $0,07^{\text {ns }}$ & $0,76^{\text {ns }}$ & $9,94^{\text {ns }}$ & $4,17^{\text {ns }}$ & $1,56^{\mathrm{ns}}$ & $24,98^{\text {ns }}$ & $8,41^{\text {ns }}$ & $0,24^{\text {ns }}$ \\
\hline C.V. (\%) & 7,03 & 4,17 & 55,14 & 43,98 & 29,05 & 37,40 & 18,34 & 30,44 \\
\hline
\end{tabular}

C.V. = coeficiente de variação; ${ }^{\text {ns: }}$ não significativo; ${ }^{*} \mathrm{p} \leq 0,05$ : significativo a $5 \%$ de probabilidade pelo teste- $t$ 


\section{Desenvolvimento da ferrugem tropical}

O número de urédias por pústula nas folhas das duas cultivares que não receberam $\mathrm{Si}$ foi maior $(35,53 \pm 0,56$ e $56,18 \pm 0,56$ para as cultivares BRS Buriti e FM 993, respectivamente) (Figura 1a,b). Nas plantas que receberam $\mathrm{Si}$, o número de urédias por pústula foi reduzido $(14,33 \pm 0,56$ e $10,98 \pm 0,56$

Tabela 2. Número de pústulas (NP) e número de urédias (NU) por $\mathrm{cm}^{2}$ em folhas das plantas de algodáo das cultivares BRS Buriti e FM 993 crescidas em solução nutritiva contendo $(+\mathrm{Si})$ ou não $(-\mathrm{Si})$ silício (Si) e infectadas por Phakopsora gossypii

\begin{tabular}{lccccc} 
Cultivares & \multicolumn{2}{c}{ NP } & & \multicolumn{2}{c}{ NU } \\
\cline { 2 - 3 } \cline { 5 - 6 } & $-\mathbf{S i}$ & $+\mathbf{S i}$ & & $-\mathbf{S i}$ & $+\mathbf{S i}$ \\
\hline BRS Buriti & $8,17 \mathrm{Ba}$ & $5,73 \mathrm{Ab}$ & & $35,53 \mathrm{Ba}$ & $14,33 \mathrm{Ab}$ \\
\hline FM 993 & $15,22 \mathrm{Aa}$ & $4,58 \mathrm{Bb}$ & & $56,18 \mathrm{Aa}$ & $10,98 \mathrm{Bb}$ \\
\hline C.V. (\%) & \multicolumn{2}{c}{9,00} & & \multicolumn{2}{c}{4,68}
\end{tabular}

Médias na mesma coluna seguidas de mesma letra maiúscula ou médias na linha seguidas de mesma letra minúscula são estatisticamente iguais $(\mathrm{p} \leq 0,05)$, de acordo com o teste de Tukey; C.V. = coeficiente de variaçăo para as cultivares BRS Buriti e FM 993, respectivamente) (Figura 1c,d).

\section{Concentração de CFST}

A concentração de CFST para as plantas da cultivar BRS Buriti supridas com $\mathrm{Si}$ apresentou um aumento até 10 dai, seguida de redução até 20 dai. Aos 25 dai ocorreu aumento (Figura 2a). A concentração em plantas da cultivar FM 993 supridas com Si decresceu até os 15 dai e posteriormente aumentou até os 30 dai, seguindo-se um decréscimo aos 35 dai (Figura $2 b)$. Diferenças significativas $(\mathrm{p} \leq 0,05)$ entre os tratamentos + Si e -Si ocorreram aos $0,10,25$ e 35 dai para a cultivar BRS Buriti, sendo esses aumentos de 15\%, 19\%, $38 \%$ e $38,5 \%$, respectivamente. Aos 0 e 30 dai ocorreram aumentos significativos entre os tratamentos $+\mathrm{Si}$ e -Si para a cultivar FM 993, sendo os aumentos de $178 \%$ e 181\%, respectivamente.
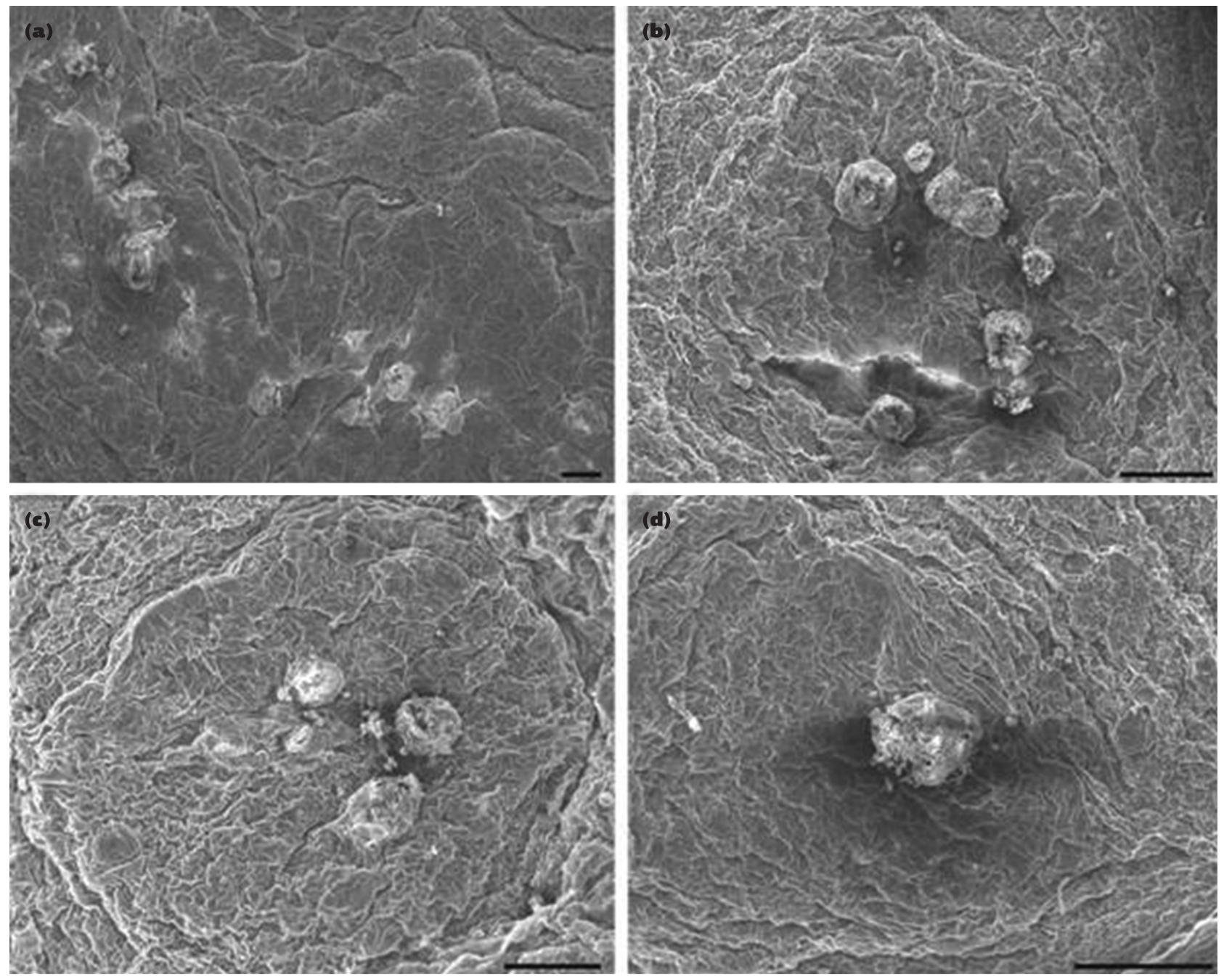

Figura 1. Eletromicrografias de varredura da superfície abaxial de folhas de algodáo das cultivares BRS Buriti (a, c) e FM 993 (b, d) crescidas em solução nutritiva sem (a, b) ou com (c, d) silício aos 35 dias após inoculaçáo com Phakopsora gossypii; barras em a = $100 \mu$ m; $\mathrm{b}, \mathrm{c}=200 \mu \mathrm{m} ; \mathrm{d}=300 \mu \mathrm{m}$. 
(a)

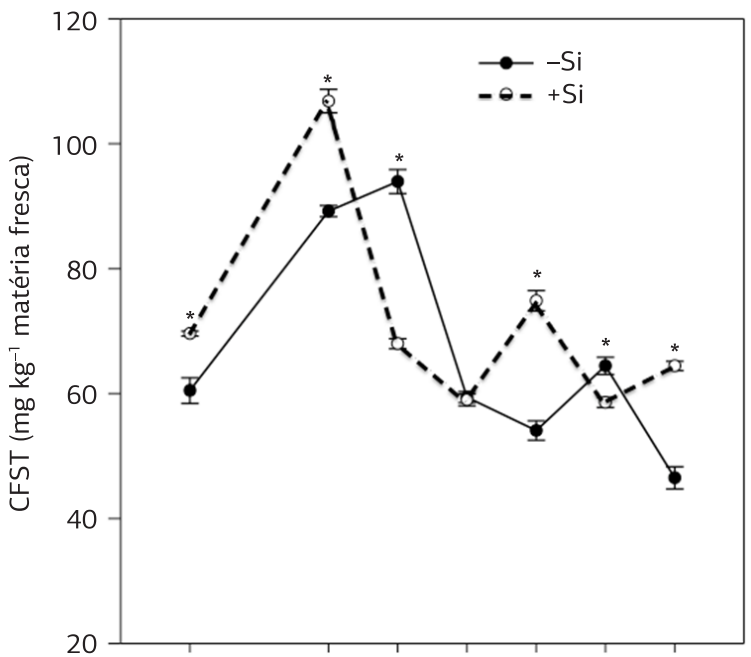

(b)

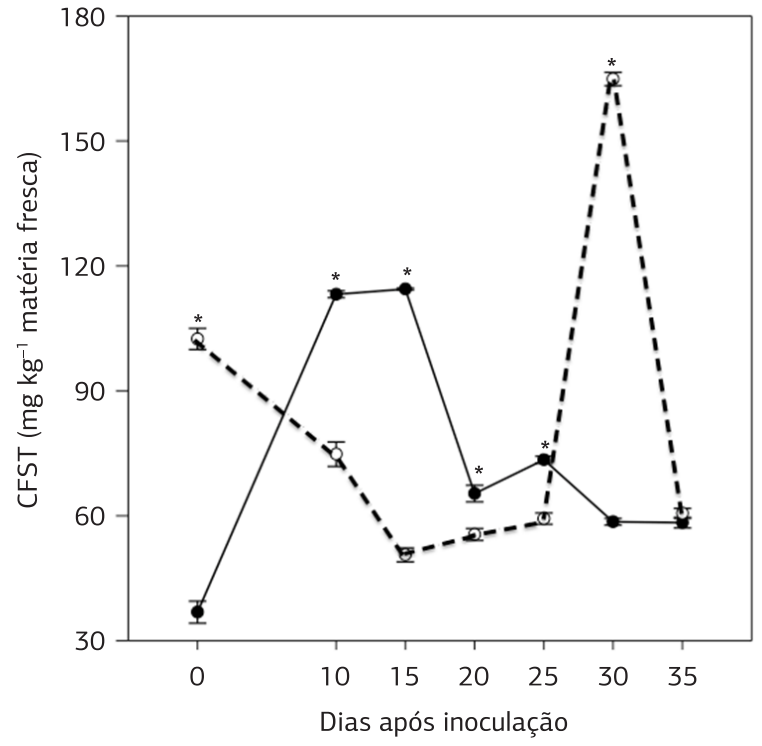

Figura 2. Concentraçấo de compostos fenólicos solúveis totais (CFST) em folhas de plantas de algodão das cultivares BRS Buriti (a) e FM 993 (b) crescidas em soluçáo nutritiva contendo (+Si) ou não $(-\mathrm{Si})$ silício $(\mathrm{Si})$ e infectadas por Phakopsora gossypii; cada ponto representa a média de quatro repetiçóes; barras de erros representam o desvio padrão da média; médias dos tratamentos $-\mathrm{Si}$ e $+\mathrm{Si}$ seguidas de asterisco $\left({ }^{*}\right)$ são diferentes $(\mathrm{p} \leq 0,05)$ pelo teste- $t$.

\section{Concentração de DLATG}

A cultivar BRS Buriti suprida com Si apresentou aumento na concentração de DLATG de modo bifásico, o primeiro até os 10 dai e o segundo aos 25 dai (Figura 3a). A cultivar FM 993 suprida com Si apresentou decréscimo até os 20 dai, seguido de aumentos até os 30 dai (Figura 3b). Diferença significativa $(p \leq 0,05)$ entre os tratamentos + Si e -Si ocorreu apenas aos 0 dai para a cultivar BRS Buriti, sendo (a)

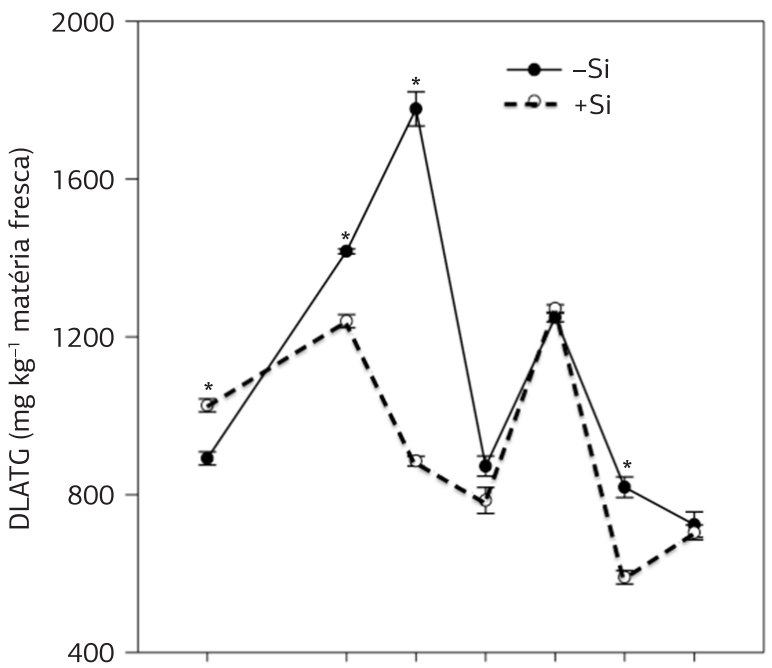

(b)

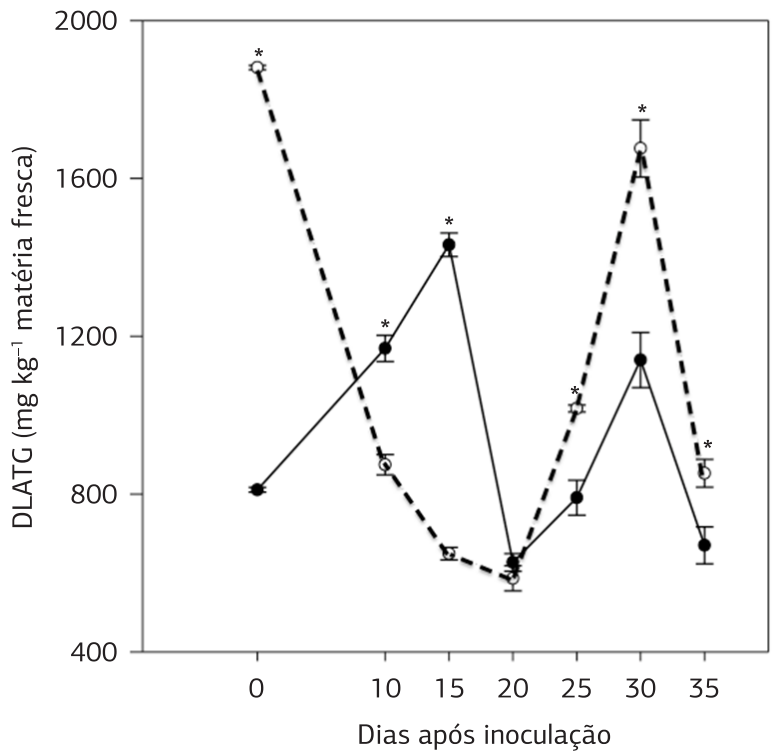

Figura 3. Concentração dos derivados da lignina-ácido tioglicólico (DLATG) em folhas de plantas de algodáo das cultivares BRS Buriti (a) e FM 993 (b) crescidas em solução nutritiva contendo (+Si) ou não $(-\mathrm{Si})$ silício $(\mathrm{Si})$ e infectadas por Phakopsora gossypii; cada ponto representa a média de quatro repetiçóes; barras de erros representam o desvio padrão da média; médias dos tratamentos $-\mathrm{Si}$ e $+\mathrm{Si}$ seguidas de asterisco $\left({ }^{*}\right)$ são diferentes $(\mathrm{p} \leq 0,05)$ pelo teste- $t$.

esse aumento de 15\%. Para a cultivar FM 993 ocorreram diferenças significativas $(\mathrm{p} \leq 0,05)$ entre os tratamentos $+\mathrm{Si}$ e - $\mathrm{Si}$ aos 0 , 25, 30 e 35 dai, de $132 \%, 28 \%$, $47 \%$ e $27 \%$, respectivamente.

\section{Atividade enzimática}

A atividade da POX na cultivar BRS Buriti suprida com Si mostrou aumentos até os 25 dai, seguidos de um decréscimo 
aos 30 dai e de outro aumento aos 35 dai. Houve aumento significativo $(\mathrm{p} \leq 0,05)$ na atividade da POX aos 25 e 35 dai (Figura 4a). Na cultivar FM 993 suprida com Si houve aumento na atividade da POX até os 10 dai e aos 20 dai, seguido de decréscimo até os 35 dai. Houve aumento significativo $(\mathrm{p} \leq 0,05)$ aos 10 e 20 dai entre os tratamentos + Si e -Si (Figura 4b).

As plantas da cultivar BRS Buriti supridas com $+\mathrm{Si}$ apresentaram aumentos na atividade da PPO até os 35 dai, sendo esses aos 25 e 35 dai. Houve aumento significativo

(a)

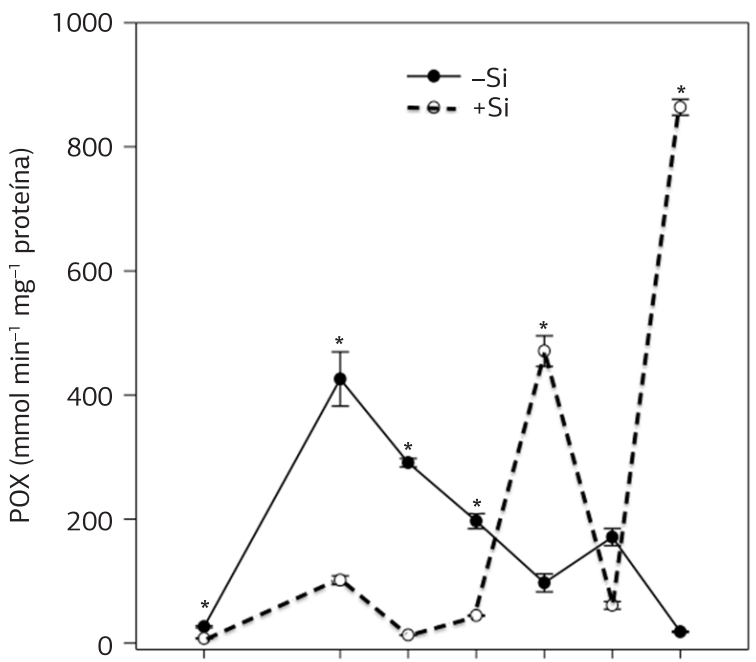

(b)

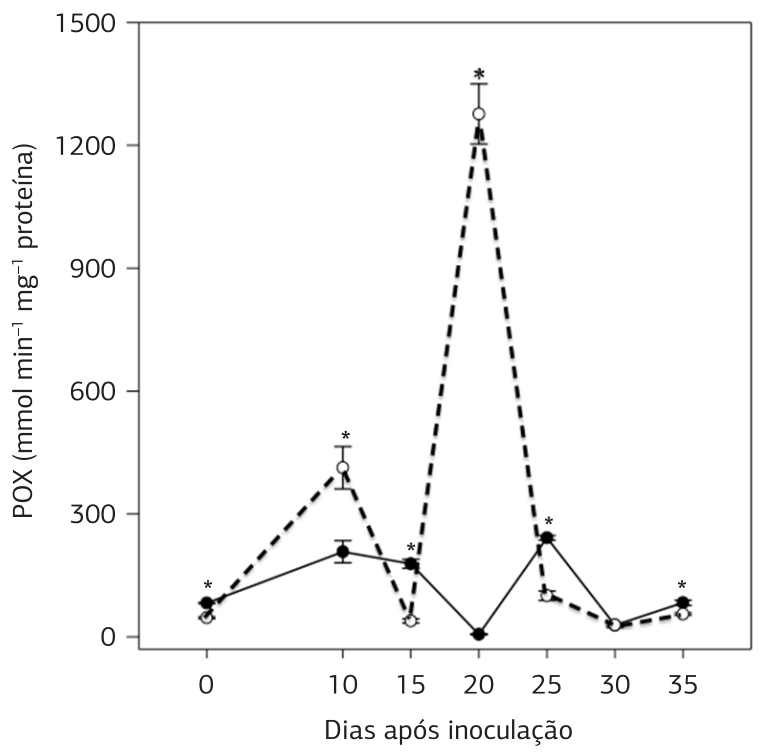

Figura 4. Atividade da peroxidase (POX) em folhas de plantas de algodão das cultivares BRS Buriti (a) e FM 993 (b) crescidas em solução nutritiva contendo $(+\mathrm{Si})$ ou não $(-\mathrm{Si})$ silício $(\mathrm{Si})$ e infectadas por Phakopsora gossypii; cada ponto representa a média de quatro repetiçóes; barras de erros representam o desvio padrão da média; médias dos tratamentos $-\mathrm{Si} \mathrm{e}+\mathrm{Si}$ seguidas de asterisco $\left({ }^{*}\right)$ são diferentes $(\mathrm{p} \leq 0,05)$ pelo teste- $t$. $(\mathrm{p} \leq 0,05)$ da PPO nas plantas supridas com Si aos 25 e 35 dai (Figura 5a). A cultivar FM 993 suprida com Si apresentou aumento da atividade da PPO até os 25 dai, seguido de decréscimo até os 35 dai. Nas plantas dessa cultivar supridas com Si não ocorreu aumento significativo $(p>0,05) \mathrm{da}$ atividade da PPO (Figura 5b).

As plantas da cultivar BRS Buriti supridas com $\mathrm{Si}$ apresentaram aumento na atividade da QUI até os 10 dai, seguido de redução até os 35 dai (Figura 6a). A cultivar FM 993 suprida com Si apresentou dois picos de atividade

(a)

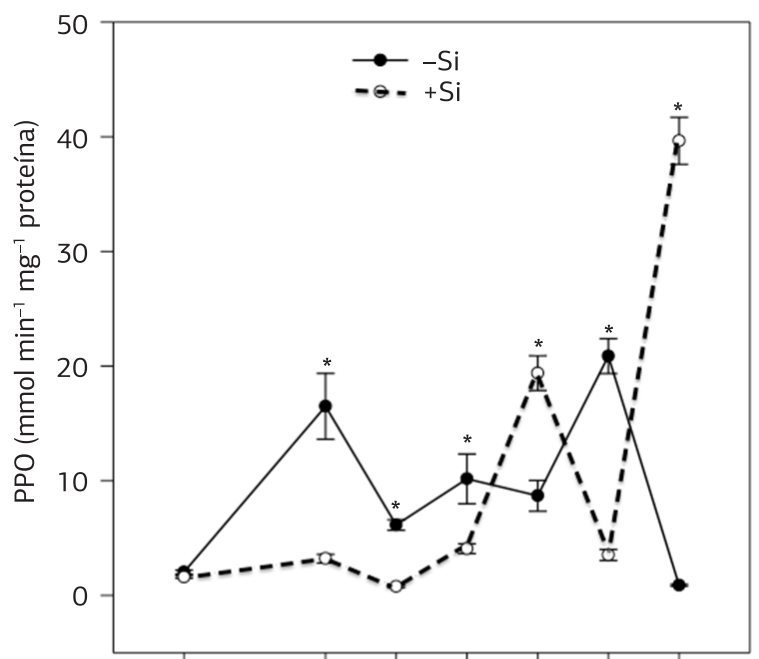

(b)

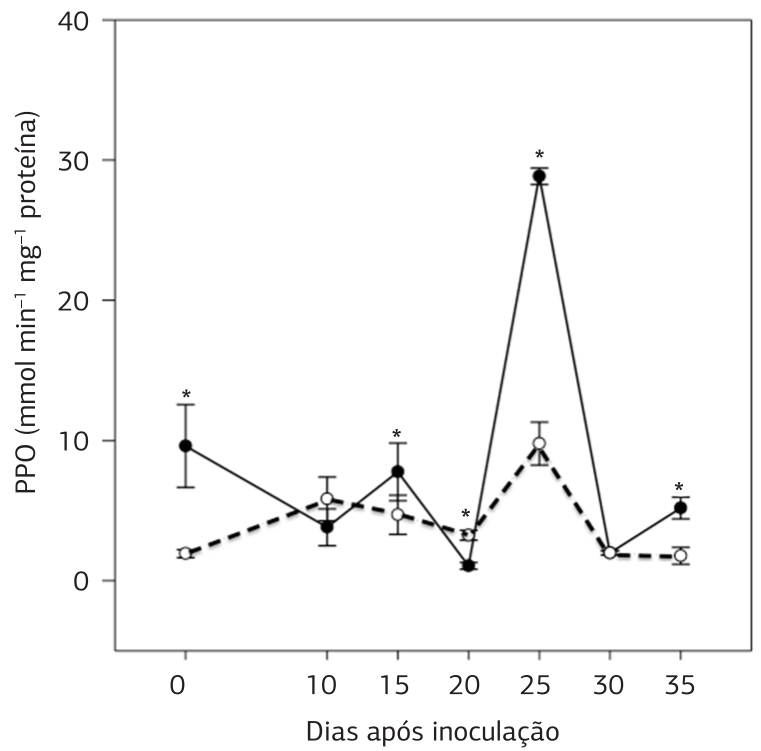

Figura 5. Atividade da polifenoloxidase (PPO) em folhas de plantas de algodáo das cultivares BRS Buriti (a) e FM 993 (b) crescidas em solução nutritiva contendo $(+\mathrm{Si})$ ou cnão $(-\mathrm{Si})$ silício $(\mathrm{Si})$ e infectadas por Phakopsora gossypii; Cada ponto representa a média de quatro repetiçôes; barras de erros representam o desvio padrão da média; médias dos tratamentos $-\mathrm{Si} \mathrm{e}+\mathrm{Si}$ seguidas de asterisco $\left(^{*}\right)$ são diferentes $(\mathrm{p} \leq 0,05)$ pelo teste- $t$. 
(a)

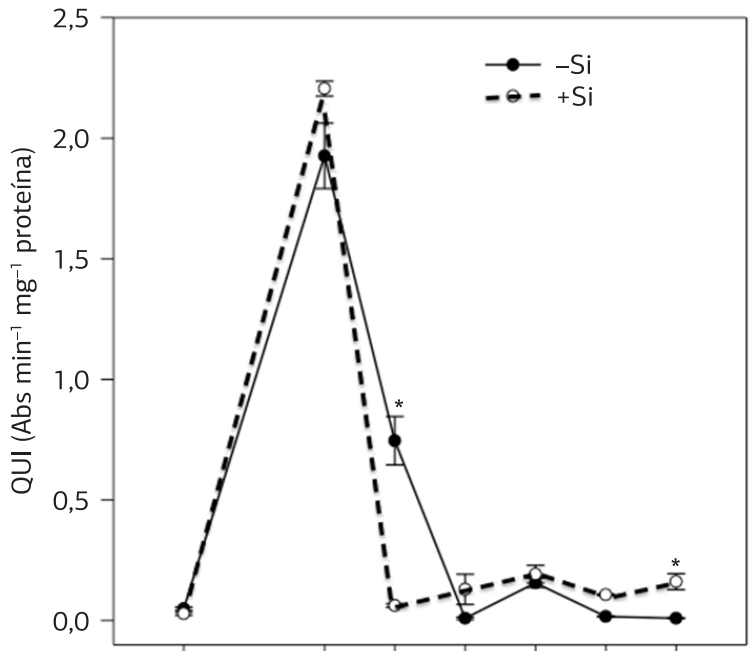

(b)

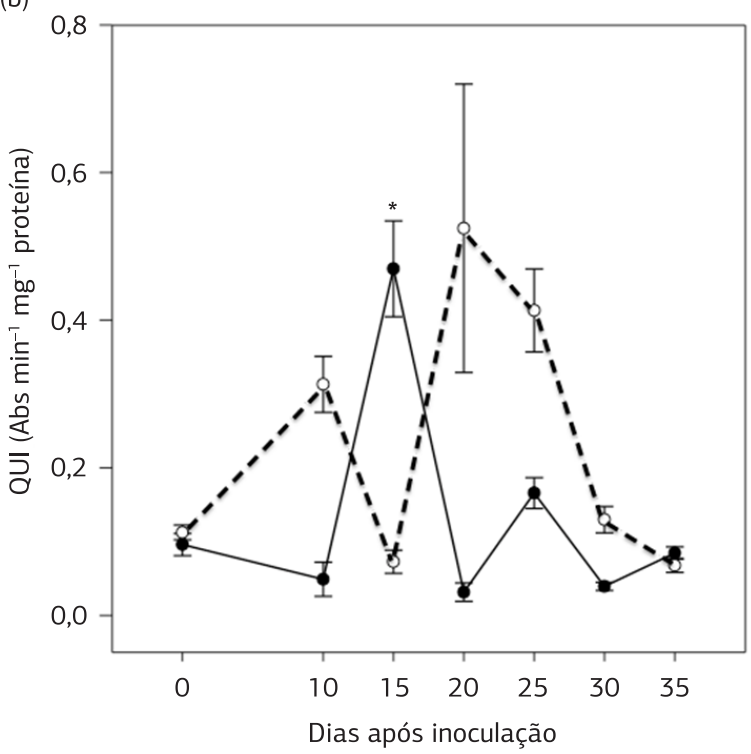

Figura 6. Atividade da quitinase (QUI) em folhas de plantas de algodão das cultivares BRS Buriti (a) e FM 993 (b) crescidas em solução nutritiva contendo $(+\mathrm{Si})$ ou não $(-\mathrm{Si})$ silício $(\mathrm{Si})$ e infectadas por Phakopsora gossypii; cada ponto representa a média de quatro repetiçôes; barras de erros representam o desvio padrão da média; médias dos tratamentos $-\mathrm{Si}$ e $+\mathrm{Si}$ seguidas de asterisco $\left({ }^{*}\right)$ são diferentes $(\mathrm{p} \leq 0,05)$ pelo teste- $t$.

da QUI, sendo um aos 10 dai e o outro aos 20 dai, seguidos de redução até os 35 dai (Figura $6 b$ ). Diferenças significativas $(p \leq 0,05)$ entre os tratamentos $+\mathrm{Si}$ e $-\mathrm{Si}$ ocorreram apenas aos 35 dai para a cultivar BRS Buriti (Figura 6a).

A atividade da GLU nas plantas da cultivar BRS Buriti supridas com Si aumentou até os 10 dai, seguindo-se decréscimo até os 35 dai (Figura 7a). A cultivar FM 993 suprida com $\mathrm{Si}$ apresentou aumentos na atividade da GLU aos 20 dai, também seguidos de redução (Figura $7 b$ ). Diferenças significativas $(\mathrm{p} \leq 0,05)$ entre os tratamentos $+\mathrm{Si}$ (a)

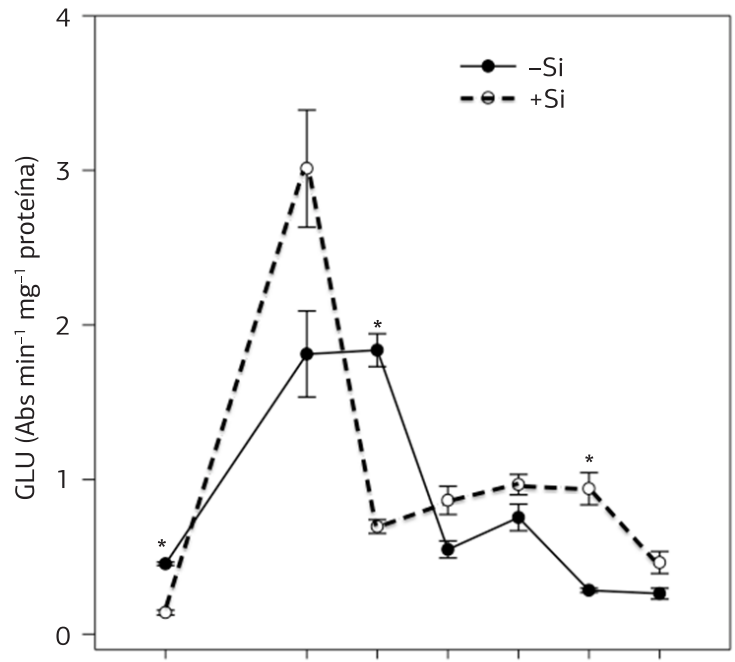

(b)

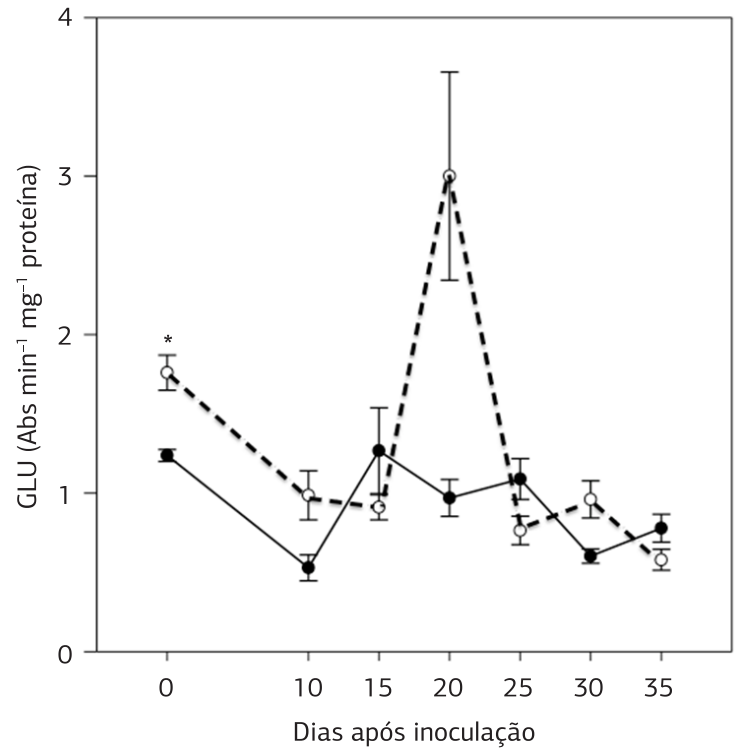

Figura 7. Atividade da glucanase (GLU) em folhas de plantas de algodão das cultivares BRS Buriti (a) e FM 993 (b) crescidas em solução nutritiva contendo $(+\mathrm{Si})$ ou não $(-\mathrm{Si})$ silício $(\mathrm{Si})$ e infectadas por Phakopsora gossypii; cada ponto representa a média de quatro repetiçôes; barras de erros representam o desvio padrão da média; médias dos tratamentos $-\mathrm{Si}$ e $+\mathrm{Si}$ seguidas de asterisco $\left({ }^{*}\right)$ são diferentes $(\mathrm{p} \leq 0,05)$ pelo teste- $t$.

e -Si ocorreram aos 30 dai, com aumento da atividade da GLU de 232\% para a cultivar BRS Buriti e apenas de $42 \%$ aos 0 dai para a cultivar FM 993.

\section{DISCUSSÃO}

A aplicação do Si reduziu a severidade final da ferrugem tropical do algodoeiro mostrando que as plantas de algodoeiro são capazes de absorver e acumular Si em seus 
tecidos, impactando negativamente o progresso da ferrugem tropical, assemelhando-se a outros estudos que mostram os efeitos benéficos do Si no controle de doenças em culturas economicamente importantes como arroz, trigo, sorgo, cevada, milho, pepino, tomate, banana, uva, rosa e morango (Datnoff et al., 2007).

O fornecimento de Si para ambas as cultivares afetou todos os componentes de resistência avaliados. PI e PL60 sofreram aumentos enquanto que I, SF, AP, AACPF, AACPAP, $\mathrm{NP}$ e NU foram reduzidos na presença do Si. ZADOKS (1971) relata que aumentos no PI podem reduzir o taxa de epidemia, tendo como consequência diminuição no número de ciclos secundários do patógeno. $\mathrm{O}$ fato de a maior concentraçáo foliar de Si reduzir alguns componentes de resistência deve-se ao fato de esse elemento poder provocar alguma interferência no acesso do patógeno aos tecidos do hospedeiro, afetando assim a sua colonização. Os resultados do presente estudo corroboram os obtidos por SHETTY et al. (2012), que observaram atraso no desenvolvimento dos sintomas e redução na severidade da doença provocada pelo míldio pulverulento em roseira suprida com Si. SAmuels et al. (1991) encontraram resultados promissores no controle do oídio em plantas de pepino cultivadas em soluçáo nutritiva contendo $100 \mathrm{mg} / \mathrm{L}$ de silicato de potássio, atribuindo-se a redução no crescimento das colônias do fungo nas folhas das plantas tratadas com $\mathrm{Si}$ ao acúmulo de $\mathrm{Si}$ ao redor das hifas. Também Resende et al. (2009) obtiveram aumento no PI e no PL60 e reduçáo da eficiência relativa de infecção e da área abaixo da curva de progresso da antracnose nas folhas de sorgo com a aplicaçáo de silicato de cálcio no solo.

$\mathrm{O}$ mecanismo de ação do Si na redução da ferrugem tropical ainda não é conhecido, mas pode-se inferir que seu efeito seja possivelmente devido à formação de barreiras (químicas e físicas) nas folhas, reduzindo-se assim o acesso de P. gossypii aos tecidos das plantas e despertando mecanismos de resistência. Conforme Bowen et al. (1992), a redução da severidade do oídio da videira também foi devida à formação de barreira física que dificultou a penetração das hifas. Domiciano et al. (2010), estudando folhas de sorgo supridas com $\mathrm{Si}$, encontraram em observaçôes feitas em microscópio eletrônico de varredura acoplado a microanálise de raios-X que a distribuição desse elemento foi uniforme em toda a superfície das folhas, seguindo um padrão linear que corresponde às células de sílica, acúmulo que impactou, levando a aumento no PI e a reduçóes no número de lesóes/ $\mathrm{cm}^{2}$, área abaixo da curva de progresso da mancha marrom e severidade da mancha marrom. Acredita-se que nas áreas da folha onde ocorre deposição de Si haja um atraso no ingresso e na colonização do fungo, permitindo-se, assim, que a planta tenha mais tempo para ativar as respostas de defesa. Além da proteção mecânica da epiderme proporcionada pelo $\mathrm{Si}$ (Yoshida et al., 1965), pode-se inferir também que o Si potencializou mecanismos de defesa da planta como, por exemplo, o acúmulo de lignina, importante componente na resistência das plantas aos patógenos (CHÉRIF et al., 1994; RODRIGUEs et al., 2004).

A atividade das enzimas POX e PPO na cultivar BRS Buriti suprida com Si foi inferior ao longo do processo infeccioso, apresentando aumentos de atividade em estágios mais avançados da doença. Na cultivar FM 993, a atividade da POX foi influenciada pelo Si ao longo do progresso da doença, enquanto que a PPO não sofreu influência do Si. Rodrigues et al. (2005) mostraram que as transcriçōes da POX aumentou durante o curso da infecção por P.grisea em ambas interaçôes incompatíveis e compatíveis em plantas de arroz com fornecimento ou privados de Si. Chérif et al. (1994), estudando a interação Pythium sp. em raízes de pepino, relataram aumento nas atividades das enzimas POX e PPO nas plantas supridas com Si. As POX têm várias funções fisiológicas que podem contribuir para a resistência da planta, como a biossíntese de compostos fenólicos (SCHMID e Feucht, 1980), ligaçóes com polissacarídeos (FrY, 1986), lignificação (WaLter, 1992) e inibição do crescimento fúngico (Маско et al., 1968). A PPO exerce um papel importante na defesa das plantas, pois oxida compostos fenólicos em quinonas, as quais são tóxicas aos patógenos, além de poder ligar-se a proteínas e carboidratos produzindo compostos que atuam como barreira física aos patógenos (Luthra et al., 1988). Neste estudo, as atividades da POX e da PPO estão associadas a aumentos nas concentraçóes de lignina e compostos fenólicos solúveis totais nas folhas, respectivamente. Esses resultados indicam que é possível que o papel exercido por essas enzimas na resistência do algodáo à $P$. gossypii esteja relacionado com o fortalecimento da parede celular, além disso é possível que a POX esteja possivelmente atuando como antioxidante.

Estudos disponíveis na literatura descrevem que a aplicação de Si pode afetar a produção de compostos fenólicos em plantas infectadas por patógenos (CARVer et al., 1998; Rodrigues et al., 2005). Os compostos fenólicos estão associados às defesas passivas e ativas das plantas aos patógenos e são encontrados tanto em interações compatíveis quanto incompatíveis (Nicholson e Hammerschmidt, 1992). No presente estudo, a concentração de CFST mostrou dois comportamentos, conforme a cultivar avaliada. Na cultivar BRS Buriti houve pico de atividade nos momentos iniciais da infecção, enquanto que a cultivar FM 993 mostrou maior atividade em estágios mais avançados da infecção - esse comportamento mostra que o Si foi capaz de aumentar a resistência das plantas de ambas cultivares. Compostos fenólicos estão relacionados aos efeitos fungitóxicos, especialmente formas oxidadas, incluindo os precursores da lignina. Os compostos fenólicos estão associados com um aumento da permeabilidade da membrana fúngica, ocasionando vazamento do conteúdo das células e agregação do citoplasma (Southerton e Deverall, 1990). A açáo do Si sobre a produção de CFST levou ao aumento da resistência das plantas de algodão à ferrugem, a qual é 
constatada pela redução em todos os componentes de resistência estudados. Nas plantas não supridas com $\mathrm{Si}$, a concentração de CFST ligeiramente superior nos estágios iniciais da infecção em ambas as cultivares foi provavelmente devida ao elevado número de penetrações bem sucedidas, o que correspondeu a maior severidade da doença conforme determinado pelos componentes de resistência estudados. Os resultados obtidos nesse estudo náo corroboram aqueles obtidos por Domiciano et al. (2010) e Xavier Filha et al. (2011) estudando, respectivamente, as interações trigoBipolaris sorokiniana e trigo-Pyricularia grisea, os quais obtiveram valores inferiores na concentração de CFST das plantas supridas com $\mathrm{Si}$, entretanto, esses foram suficientes para reduzir a severidade das doenças. Os resultados obtidos neste estudo suportam a hipótese de o Si contribuir para aumentar a concentração de CFST e de que esse pode ser considerado como um dos mecanismos de defesa que conferem resistência à ferrugem.

Foi demonstrado que o fornecimento de Si para a cultivar BRS Buriti contribuiu para que as maiores concentraçóes de DLATG acontecessem nos estágios iniciais do processo infeccioso, enquanto que na cultivar FM 993 ocorressem em estágios mais avançados, de modo que o Si contribuiu para aumentar resistência do algodáo à doença. Esses resultados foram semelhantes aos encontrados por RodRIGUes et al. (2005), que observaram que a concentração de derivados DLATG foi bifásica nas cultivares de arroz inoculadas com P. grisea. O acúmulo de DLATG foi menor em folhas de plantas da cultivar M201 (suscetível) supridas com Si. Isso mostra que as células da planta, mesmo com menores concentraçóes de DLATG, foram eficientemente protegidas contra a colonização de $P$. gossypii.

Aumentos nas atividades da QUI e GLU em ambas as cultivares supridas com Si contribuíram para a redução da doença, principalmente nos estágios iniciais, exceto para a GLU na cultivar FM 993, que foi maior em estágios intermediários. Quitinases e glucanases em plantas são enzimas importantes, componentes do sistema de defesa, não só porque podem inibir o crescimento de fungos mas por provocar a dissolução das paredes das células fúngicas elas também são capazes de liberar oligômeros de quitina, que provocam outras importantes reaçóes de defesa celular, como a produção de compostos fenólicos e o aumento na biossíntese de lignina (Leubner-Metzgerand e Meinns JúNIOR, 1999). De modo geral, a possível dissolução das paredes e degradação das hifas do patógeno levaram a uma menor eficiência no processo de colonização dos tecidos do hospedeiro. Os resultados desse estudo não se assemelham aos obtidos por Domiciano et al. (2010), que mostraram que a atividade da QUI foi alta nos estágios mais avançados de infecção por B. sorokiniana nas folhas de duas cultivares de trigo supridas com Si. Pereira et al. (2009) mostraram que aplicaçôes foliares de silicato de potássio no patossistema café-Hemileia vastatrix aumentaram a atividade da QUI e da GLU em estádios intermediários do processo infeccioso. Portanto, pode-se inferir que as atividades das enzimas QUI e GLU pode estar associada a mecanismos de defesa das plantas de ambas as cultivares supridas com $\mathrm{Si}$, impedindo que o patógeno penetre, cresça e colonize as células do tecido foliar, como a redução dos componentes de resistência avaliados evidencia.

\section{CONCLUSÃO}

Plantas de algodão supridas com Si têm a resistência à ferrugem tropical aumentada, devido à maior atividade das enzimas de defesa.

\section{AGRADECIMENTOS}

À Fundação de Amparo à Pesquisa do Estado de Minas Gerais (FAPEMIG), pelo recurso financeiro (Processo APQ-0115909). Ao Conselho Nacional de Desenvolvimento Científico e Tecnológico (CNPq), pelas bolsas de doutorado e iniciação científica concedidas a A. M. N. M. Guerra e A. F. Barros e pelas bolsas de produtividade em pesquisa dos professores $\mathrm{F}$. A. Rodrigues e P. G. Berger. Os autores agradecem ao Núcleo de Microscopia e Microanálise (CCB/UFV) pela utilização do MEV e pelos equipamentos auxiliares utilizados nas análises microscópicas e à Fundação de Amparo à Pesquisa do Estado de Minas Gerais - FAPEMIG (APQ-01159/09), CNPq e FINEP pelo apoio financeiro.

\section{REFERÊNCIAS}

BARBER, M.S.; RIDE, J.P. A quantitative assay for induce lignification in wounded wheat leaves and its use to survey potential elicitors of the response. Physiological and Molecular Plant Pathology, v.32, p.185-197, 1988. http://dx.doi.org/10.1016/S0885-5765(88)80015-8

BÉLANGER, R.R.; BENHAMOU, N.; MENZIES, J.G. Cytological evidence of an active role of silicon in wheat resistance to powdery mildew (Blumeria graminis f.sp. tritici). Phytopathology, v.93, p.402-412, 2003. PMid:18944354. http://dx.doi.org/10.1094/ PHYTO.2003.93.4.402

BENEDO, I.P. Ferrugens. In: BERGAMIN FILHO A.; KIMATI H.; AMORIM L. (Ed.). Manual de fitopatologia. São Paulo. Agronômica Ceres, 1995. p.872-880.

BOWEN, P.; MENZIES, J.; EHRET, D. Soluble silicon spray inhibit powdery mildew development on grape leaves. Journal of the American Society for Horticultural Science, v.117, p.906-912, 1992.

BRADFORD, M.M. A rapid and sensitive method for the quantitation of microgram quantities of protein utilizing the principle of proteindye binding. Analytical Biochemistry, v.72, p.248-254, 1976. http:// dx.doi.org/10.1016/0003-2697(76)90527-3 
CARVER, T.L.W.; ROBBINS, M.P.; THOMAS, B.J.; TROTH, K.; RAISTRICK, N.; ZEYEN, R.J. Silicon deprivation enhances localized autofluorescent responses and phenylalanine ammonia-lyase activity in oat attacked by Blumeria graminis. Physiological and Molecular Plant Pathology, v.52, p.245-257, 1998. http://dx.doi.org/10.1006/ pmpp.1998.0149

CHANCE, B.; MAEHLEY, A.C. Assay of catalases and peroxidases. Methods in Enzymology, v.2, p.764-775, 1955. http://dx.doi. org/10.1016/S0076-6879(55)02300-8

CHÉRIF, M.; ASSELIM, A.; BÉLANGER, R.R. Defense responses induced by soluble silicon in cucumber roots infected by Pythium spp. Phytopathology, v.84, p.236-242, 1994. http://dx.doi.org/10.1094/ Phyto-84-236

DATNOFF, L.E.; RODRIGUES, F.A.; SEEBOLD, K.W. Silicon and Plant Disease. In: DATNOFF, L.E.; ELMER, W.H.; HUBER, D.M. (Ed.). Mineral Nutrition and Plant Disease. St. Paul: The American Phytopathological Society, 2007. p.233-246.

DOMICIANO, G.P.; RODRIGUES, F.A.; VALE, F.X.R.; XAVIER FILHA, M.S.; MOREIRA, W.R.; ANDRADE, C.C.L.; PEREIRA, S.C. Wheat resistance to spot blotch potentiated by silicon. Journal of Phytopathology, v.158, p.334-343, 2010. http://dx.doi.org/10.1111/ j.1439-0434.2009.01623.x

EPSTEIN, E. Silicon. Annual Review of Plant Physiology and Plant Molecular Biology, v.50, p.641-664, 1999. PMid:15012222. http:// dx.doi.org/10.1146/annurev.arplant.50.1.641

FREIRE, E.C. História do algodão no Cerrado. In: FREIRE, E.C. (Ed.). Algodáo no Cerrado do Brasil. Brasília: Abrapa, 2011. p.21-52.

FRENCH-MONAR, R.D.; RODRIGUES, F.A.; KORNDÖRFER, G.H.; DATNOFF, L.E. Silicon suppresses Phytophtrora blight development on bell pepper. Journal of Phytopathology, v.158, p.554-560, 2010.

FRY, S.C. Cross-linking of matrix polymers in the growing cell walls of angiosperms. Annual Review Plant Physiology, v.37, p.165-186, 1986. http://dx.doi.org/10.1146/annurev.pp.37.060186.001121

HARMAN, G.E.; HAYES, C.K.; LORITO, M.; BROADWAY, R.M.; PIETRO, A.D.; PETERBAUER, C.; TRONSMO, A. QUItinolytic enzymes of Trichoderma harzianum: purification of QUItobiosidase and endoQUItinase. Phytopathology, v.83, p.313-318, 1993. http:// dx.doi.org/10.1094/Phyto-83-313

HOAGLAND, D.R.; ARNON, D.I. The water culture method for growing plants without soil. California Agricultural Experiment Station, v.347, p.32, 1950.

HUANG, C.H.; ROBERTS, P.D.; DATNOFF, L.E. Silicon suppresses Fusarium crown and root rot of tomato. Journal of Phytopathology, v.159, p.546-554, 2011. http://dx.doi.org/10.1111/j.14390434.2011.01803.x

KAR, M.; MISHRA, D. Catalase, peroxidase and polyphenoloxidase activities during rice leaf senescence. Plant Physiology, v.57, p.315319, 1976. PMid:16659474 PMCid:PMC542015. http://dx.doi. org/10.1104/pp.57.2.315

KIM, S.G.; KIM, K.W.; PARK, E.W.; CHOI, D. Silicon-induced cell wall fortification of rice leaves, a possible cellular mechanism of enhanced host resistance to blast. Phytopathology, v.92, p.1095-1103, 2002. PMid:18944220. http://dx.doi.org/10.1094/PHYTO.2002.92.10.1095

KORNDÖRFER, G.H.; PEREIRA, H.S.; NOLLA, O.A. Análise de silício: solo, planta e fertilizante. Uberlândia: Grupo de Pesquisa em Silício, ICIAG, Universidade Federal de Uberlândia, 2004. 34p.

LEUBNER-METZGERAND, G.; MEINNS JUNIOR, F. Functions and regulation of plant $\beta$-1,3-glucanases (PR-2). In: DATTA, S.K.; MUTHUKRISANAN, S. (Ed.) Pathogenesis-related proteins in plants. Boca Raton, Florida. CRC Press LLC, 1999. p.49-76. http:// dx.doi.org/10.1201/9781420049299.ch3

LEVER, M. A new reaction for colorimetric determination of carbohydrates. Analytical Biochemistry, v.47, p.273-279, 1972. http://dx.doi.org/10.1016/0003-2697(72)90301-6

LUTHRA, Y.P.; GHANDI, S.K.; JOSHI, U.N.; ARORA, S.K. Total phenolic compounds and their oxidative enzymes in sorghum leaves resistant and susceptible to Ramulispora sorghicola Harris. Acta Phytopathologica et Entomologica Hungarica, v.23, p.393-400, 1988.

MA, J.F.; TAKAHASHI, E. Soil, fertilizer and plant silicon research in Japan. Amsterdam: Elsevier Science Academic Press, 2002. 281p.

MACKO, V.; WOODBURY, W.; STAHMANN, M.A. The effect of peroxidase on the germination and growth on mycelium of Puccinia graminis f.sp. tritici. Phytopathology, v.58, p.1250-1254, 1968.

MARUR, C.J.; RUANO, O. A reference system of determination of cotton plant development. Revista Brasileira de Oleaginosas e Fibrosas, v.5, p.313-317, 2001.

MENZIES, J.; EHRET, D.L.; GLASS, A.D.M.; SAMUELS, A.L. The influence of silicon on cytological interactions between Sphaerotheca fuliginea and Cucumis sativus. Physiological and Molecular Plant Pathology, v.39, p.403-414, 1991. http://dx.doi.org/10.1016/08855765(91)90007-5

NICHOLSON, R.L.; HAMMERSCHMIDT, R. Phenolic compound and their role in disease resistance. Annual Review of Phytopathology, v.30, p.369-389, 1992. http://dx.doi.org/10.1146/annurev. py.30.090192.002101

PEREIRA, S.C.; RODRIGUES, F.A.; CARRÉ-MISSIO, V.; OLIVEIRA, M.G.A.; ZAMBOLIM, L. Efeito da aplicação foliar de silício na resistência à ferrugem e na potencialização da atividade de enzimas de defesa em cafeeiro. Tropical Plant Pathology, v.34, p.223230, 2009. http://dx.doi.org/10.1590/S1982-56762009000400004

PNITHALINGAM, E. Phakopsora gossypii. C.M.I Descriptions of Pathogenic Fungi and Bacteria, v.172, p.1-2, 1968.

RESENDE, R.R.; RODRIGUES, F.A.; SOARES, J.M.; CASELA, C.R. Influence of silicon on some components of resistance to anthracnose in susceptible and resistant sorghum lines. European Journal of Plant Pathology, v.124, p.533-541, 2009. http://dx.doi. org/10.1007/s10658-009-9430-6

ROBERTS, W.K.; SELITRENNIKOFF, C.P. Plant and bacterial quitinases differ in antifungal activity. Journal of General Microbiology, v.134, p.169-176, 1988.

RODRIGUES, F.A.; JURICK, W.M.; DATNOFF, L.E.; JONES, J.B.; ROLLINS, J.A. Silicon influences cytological and molecular events in compatible and incompatible rice-Magnaporthe grisea interactions. 
Physiological and Molecular Plant Pathology, v.66, p.144-159, 2005. http://dx.doi.org/10.1016/j.pmpp.2005.06.002

RODRIGUES, F.A.; McNALLY, D.J.; DATNOFF, L.E.; JONES, J.B.; LABBÉ, C.; BENHAMOU, N.; MENZIES, J.G.; BÉLANGER, R.R. Silicon enhances the accumulation of diterpenoid phytoalexins in rice: a potential mechanism for blast resistance. Phytopathology, v.94, p.177-183, 2004. PMid:18943541. http://dx.doi.org/10.1094/ PHYTO.2004.94.2.177

RODRIGUES, F.A.; BENHAMOU, N.; DATNOFF, L.E.; JONES, J.B.; BÉLANGER, R.R. Ultrastructural and cytochemical aspects of silicon-mediated rice blast resistance. Phytopathology, v.93, p.535-546, 2003. PMid:18942975. http://dx.doi.org/10.1094/ PHYTO.2003.93.5.535

SAMUELS, A.L.; GLASS, A.D.M.; EHRET, D.L.; MENZIES, J.G. Mobility and deposition of silicon in cucumber plants. Plant, Cell and Environment, v.14, p.485-492, 1991. http://dx.doi. org/10.1111/j.1365-3040.1991.tb01518.x

SCHMID, P.S.; FEUCHT, W. Tissue-specific oxidative browning of polyphenols by peroxidase in cherry shoots. Gartenbauwissenschaft, v.45, v.68-73, 1980.

SHANER, G.; FINNEY, R.E. The effect of nitrogen fertilization on the expression of slow-mildewing resistance in Knox wheat. Phytopathology, v.67, p.1051-1056, 1977. http://dx.doi.org/10.1094/Phyto-67-1051

SOUTHERTON, S.G.; DEVERALL, B.J. Changes in phenolic acid levels in wheat leaves expressing resistance to Puccinia recondite f.sp. tritici. Physiological and Molecular Plant Pathology, v.37, p.437450, 1990. http://dx.doi.org/10.1016/0885-5765(90)90035-V

SHETTY, R.; JENSE, B.; SHETTY, N.P.; HANSEN, M.; HANSEN, C.W.; STARKEY, K.R.; JORGENSEN, H.J.L. Silicon induced resistance against powdery mildew of roses caused by Podosphaera pannosa. Plant Pathology, v.61, p.120-131, 2012. http://dx.doi. org/10.1111/j.1365-3059.2011.02493.x

STERNE, R. Tropical rust. In: WATKINS, G.M. (Ed.) Compendium of cotton disease. American Phytopathological Society, 1981. 39p.

SUASSUNA, N.D.; ARAÚJO, A.E. Ferrugem Tropical do Algodoeiro. Campina Grande: Embrapa Algodão, 2003. (Embrapa Algodão: Documentos, n.114).

VERMEIRE, M.L.; KABLAN, L.; DOREL, M.; DELVAUX, B.; RISĖDE, J.M.; LEGRÈVE, A. Protective role of silicon in the bananaCylindrocladium spathiphylli pathosystem. European Journal of Plant Pathology, v.131, p.621-630, 2011. http://dx.doi.org/10.1007/ s10658-011-9835-x

WALTER, M.H. Regulation of lignification in defense. In: BOLLER, T.; MEINS, F. (Ed.) Genes Involved in Plant Defense. New York: Springer-Verlag, 1992. p.327-352. PMid:1568117. http://dx.doi. org/10.1007/978-3-7091-6684-0_13

YOSHIDA, S. Chemical aspects of the role of silicon in physiology of the rice plant. Bulletin of the National Institute of Agricultural Science Series, v.15, p.1-58, 1965.

XAVIER FILHA, M.S.; RODRIGUES, F.A.; DOMICIANO, G.P.; OLIVEIRA, H.V.; SILVEIRA, P.R.; MOREIRA, W.R. Wheat resistance to leaf blast mediated by silicon. Australasian Plant Pathology, v.40, p.28-38, 2011. http://dx.doi.org/10.1007/s13313-010-0010-1

ZADOKS, J.C. Systems analysis and the dynamics of epidemics. Phytopathology, v.61, p.600-610, 1971.

ZIESLIN, N.; BEN-ZAKEN, R. Peroxidase activity and presence of phenolic substances in peduncles of rose flowers. Plant Physiology and Biochemistry, v.40, p.333-339, 1993. 